\title{
The effects of fish gender on susceptibility to acute Streptococcus agalactiae infection in Javanese medaka Oryzias javanicus
}

\begin{abstract}
This study describes the susceptibility of different fish gender following acute Streptococcus agalactiae infection by using Javanese medaka Oryzias javanicus as test fish. The fish were grouped into four groups, which were: (1) all-male; (2) all-female; (3) mixed-gender (1 male: 1 female ratio); and (4) control non-infected (1 male: 1 female ratio). The fish in group 1, 2 and 3 were intraperitoneally exposed to $5.4 \times 10^{8} \mathrm{CFU} / \mathrm{mL}$ of S. agalactiae, while for group 4 , the fish were exposed using sterile broth. The main clinical signs and histopathological changes of infected Javanese medaka were commonly observed in $S$. agalactiae infected fishes. However, no difference on clinical signs and histopathological changes of fish in group 1, 2 and 3 were noticed. The Javanese medaka mortality in group 1, 2 and 3 were observed from $4 \mathrm{~h}$ post infection (hpi) to $6 \mathrm{hpi}$, with the cumulative mortality from $3 \%$ to $30 \%$. Then, the mortality increased at $12 \mathrm{hpi}$, with the range from $53 \%$ to $80 \%$. However, $100 \%$ of the infected fish dead at 24 hpi. No clinical sign, histopathological change and fish mortality recorded in group 4 . Generally, the clinical signs, mortality patterns, cumulative mortality and histopathological changes of Javanese medaka infected by $S$. agalactiae did not show any difference between the all-male, all-female and mixed-gender groups. This indicates that the susceptibility of fish to $S$. agalactiae infection is not influenced by their gender.
\end{abstract}

Keyword: Susceptibility; Fish gender; Streptococcus agalactiae; Javanese medaka; Test organism 